\title{
Causes of Health Expenditure Growth: the Predominance of Changes in Medical Practices Over Population Ageing
}

\author{
Brigitte DORMONT ${ }^{*}$ and Hélène HUBER ${ }^{\dagger}$
}

\begin{abstract}
On the basis of French individual data, this paper compares the effects of demographic change, changes in morbidity and changes in practices on the growth in health expenditures that occurred between 1992 and 2000. Micro simulations show that the rise in expenditures due to ageing is relatively small and that the impact of changes in practices is 3.8 times larger. Furthermore, changes in morbidity induce savings which more than offset the increase in spending due to population ageing.
\end{abstract}

\section{Les causes de la croissance des dépenses de santé : la prédo- minance des changements de pratiques sur le vieillissement}

RÉSUMÉ. - Cet article compare, sur données individuelles françaises, les effets sur la croissance des dépenses de santé, observée entre 1992 et 2000 , des changements démographiques, des changements de pratiques médicales et des changements de morbidité. Des micro-simulations montrent que la croissance des dépenses attribuable au vieillissement est relativement faible. L'impact des changements de pratique est 3.8 fois plus élevé. En outre, les changements de morbidité induisent des économies qui compensent largement l'effet du vieillissement.

We are grateful for helpful comments from Chantal Cases (IRDES), Michel Lubrano (University of Marseille), Michel Grignon (McMaster University), Dominique Polton (CNAMTS) and Catherine Sermet (IRDES). We also thank the participants of the Fourgeaud, LEGOS, INED and DELTA seminars in Paris and of the IEMS seminar (University of Lausanne) as well as the participants of the third Journées Louis-André GérardVaret (Marseille) for useful comments. We also wish to thank two anonymous referees whose comments helped us to improve the paper. Any errors are our responsibility.

* B. Dormont: LEGOS, Université Paris Dauphine, Place du Maréchal de Lattre de Tassigny, 75016 Paris, France and IEMS Lausanne, Switzerland - brigitte.dormont@ dauphine.fr

$\dagger$ H. HubER: IRDES, Paris and EconomiX, Université Paris 10, 200, avenue de la République, 92001 Nanterre Cedex, France - helene.huber@u-paris10.fr 


\section{Introduction}

Population ageing is often considered a major determinant of the future evolution of health care expenditures. Indeed, individual health care expenditure is an increasing function of age. As life expectancy keeps improving in developed countries, the growing proportion of elderly people should lead mechanically to accelerated growth of total health care expenditures. The consequences of ageing are addressed by numerous macro and micro-economic papers. At the macro-economic level, the vast majority of studies find out that the age structure of a country is not significant in a regression explaining the level of total health care expenditures, whereas factors like GDP or level of education are highly significant (Bac et al., 2002; Gerdtham et al., 1992, 1998; Getzen, 1992; Hitiris et al., 1992; Leu, 1986; O'Connell, 1996; OECD, 1987). At the individual level, micro-economic studies also show that ageing (represented by the individual's calendar age) has a negligible influence on individual health care expenditures, when proximity to death is taken into account (Zweifel et al., 1999; Seshamani et al., 2004a and 2004b).

According to Zweifel et al. (1999), the correlation observed between age and health care expenditures is spurious: it results from the fact that the probability of death increases with age, associated with the high cost of dying ${ }^{1}$. According to this analysis, individual health care expenditures should depend exclusively on proximity to death, and not on age. These findings are likely to explain the small impact of ageing at the macro level. As stated by Stearns and Norton (2004), predictions failing to take proximity to death into account might even be misleading, resulting in an overstated effect of ageing on future health expenditures.

The effect of ageing on health care expenditures is usually thought to result from the combination of two phenomena: population ageing and the fact that health care expenditures increase with age. Until recently, most projections of future health care expenditures simulated the impact of ageing by simply applying demographic projections to the observed expenditure profile.

However, changes in health care expenditure level also depend on changes over time in the profile by age group. Figure 1 presents these profiles computed for the years 1992 and 2000. Age group 0 corresponds to people age 0-9, age group 10 to people age 10-19, and so on, until age group 70, which is related to people age 70 and over. As expected, expenditures increase with age. The main feature of the graph, however, is that a sizeable upward drift of the profile is observed between 1992 and 2000. This drift is linked to changes in patients' behaviour and in physicians' practices, as well as to technological progress. As we will show, it cannot be linked to changes in the health condition of patients, since our data reveal that they are in better shape over time.

Consequently, the increase in total health care expenditures in France can be explained by three distinct factors: $(i)$ the pure demographic effect (namely, the increase in the number and proportion of elderly people, given that health expenditure is an increasing function of age); (ii) changes in morbidity at a given age; (iii) changes in practices, for a given age and morbidity level. This can be linked to

1. For Medicare, payments per person-year for decedents are 7 times larger than for survivors; in France, the corresponding coefficient is equal to 5 . 
FIGURE 1

Average individual health care expenditures by age group, years 1992 and 2000

Mean health care expenditure by age group - 1992 and 2000

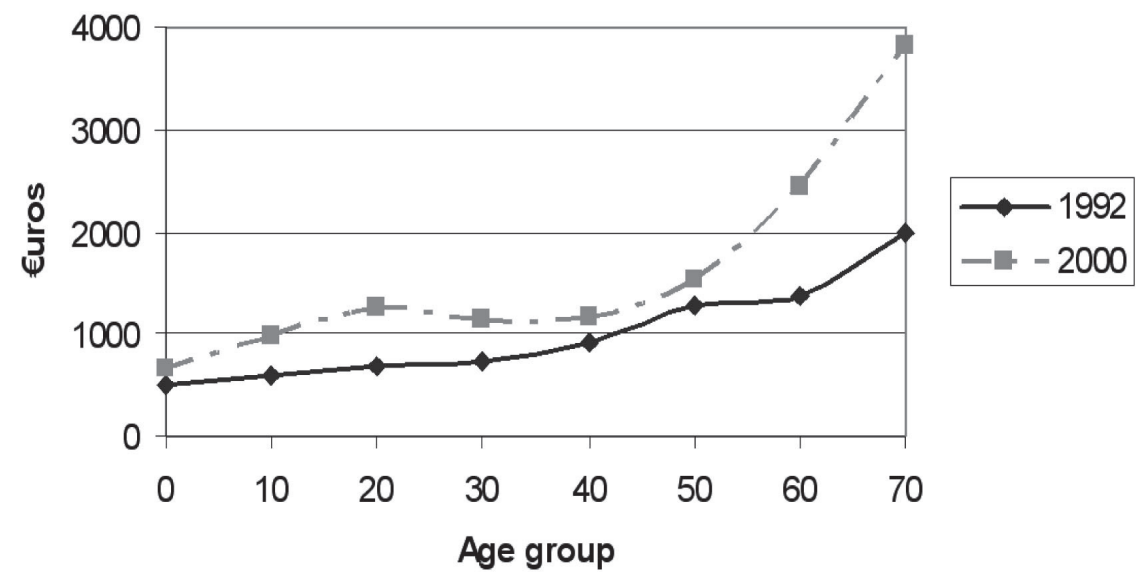

technological progress and changes in behaviour. The aim of this paper is basically to disentangle, evaluate and interpret the respective effects of these three factors.

Our data is a representative sample of 3,441 and 5,003 French individuals observed in 1992 and 2000. We use microsimulation techniques to evaluate retrospectively the components of the drift observed between 1992 and 2000 in the age profile of health expenditures. Our results show that changes in morbidity induce a downward drift of the health care expenditures profile, whereas the drift due to changes in practices is upward and sizeable.

Once we have evaluated the respective influences of changes in morbidity and changes in practices at the microeconomic level, we apply our results to the age structure of the French population to compare the aggregate effects of demographic change and profile drifts for the period 1992-2000. At the macroeconomic level, the rise in health care expenditures due to demographic change is very small, in comparison with the effects of changes in practices. For total expenditures, we find that the impact of changes in practices is 3.8 times larger than the rise in health care expenditures due to changes in the age structure of the population.

In comparison with studies that concentrate on time to death (Zweifel et al., 1999; Seshamani et al., 2004a et 2004b), our database presents the advantage of providing information not only about "death risk", which is an indicator of death proximity, but also about several other morbidity indicators. Furthermore, rather than studying only hospital expenditures, like Seshamani et al. or aggregate individual expenditures, like Zweifel et al., our dataset allows us to study the different components of individual health care expenditures: home and office physician visits, pharmaceutical expenditures submitted to reimbursement, and hospital expenditures. This detailed analysis allows us to take differences between these various kinds of expenditures into account. For example, pharmaceutical and hospital costs are much influenced by technological progress, unlike physician visits. 
The paper is organized as follows. In the next section, we present the basic features of the data and discuss access to care for the elderly in the French health care system. Then, we study the relation between morbidity and age (section 3 ). The empirical approach is presented in section 4 . The microeconometric results are presented in section 5. Section 6 compares the effects of ageing and changes in practices at the macro level. Section 7 concludes.

\section{The Data}

\subsection{The French Health Care System}

The French health insurance system is public and universal. About $99 \%$ of the population is covered, without age restriction: coverage is continuous over the entire life span. For the period under study, the insurance system grants unlimited access to care, without frequency restrictions. This system covers almost $100 \%$ of hospital care expenditures and $70 \%$ of ambulatory care expenditures. A complementary insurance can be subscribed. It may result from a decision of the individual, but is more often provided by the employer. $80 \%$ of the population has subscribed a complementary insurance, which covers the remaining $30 \%$ of the individual ambulatory care expenditures. Notice that in France specialist consultations mostly take place in ambulatory care and not within hospital. Ambulatory care coverage entails pharmaceutical expenditures ${ }^{2}$. In France, the overall value of drug prescriptions is growing rapidly because of the rising prices of innovations newly allowed on the market. On the whole, whereas the number of physician visits increased by $18 \%$ between 1992 and 2000, pharmaceutical expenditures increased by 59\% (IRDES, 2002).

Thanks to their coverage, French elderly do not face financial constraints which could limit their access to health care. In addition, since they have been well covered during their whole life before turning 65 , there is no reason why health care expenditures should rise at this age (this rise can indeed be observed in the US, where people can delay care until they become eligible for Medicare). Being continuous over the lifetime, coverage is thus unlikely to influence the profile of health expenditures by age group.

A characteristic of the period we are interested in is the modification of the medical practices, notably concerning the aged. For example, medical recommendations for preventing hypercholesterolaemia have been recently extended to very old ages in France. In the same way, the use of surgical treatment of cataract changed dramatically for people aged 75-84 in France: the proportion of surgical treatment rose from $40 \%$ to $55 \%$ between 1993 and 1998 (Baubeau et al., 2001). Another example is the increasing use of angioplasty for the treatment of Acute Myocardial Infarction. In France, the proportion of treatment by angioplasty rose from $9.6 \%$ in 1993 to $22 \%$ in 2001 for people aged 75-84 (Oberlin et al., 2004) . On the demand side, changing

2. This contrasts strongly with other systems, such as Medicare in the US or public coverage that prevails in many provinces of Canada. In 2000, for instance, Medicare in the US did not cover medication when it was not prescribed in hospital. 
preferences towards a better well-being of the elderly can explain this increasing use of innovative procedures. On the supply side, technological progress leads to better outcomes and safety which allow the extension of innovative procedures to older people. This might indeed lead to higher costs, but to considerably better well-being for the elderly.

\subsection{The Dataset}

We make use of a micro-economic data set concerning 3441 insured French citizens for the year 1992 and 5003 for the year 2000. This data set results from a survey (SPS, i.e. Santé Protection Sociale) conducted by IRDES ${ }^{3}$ on a subsample drawn from administrative data ${ }^{4}$ provided by the French public health insurance, which records every health expenditure submitted to reimbursement by subscribers (salaried workers, retired salaried workers, and their family).

The sample gives us reliable information about each individual's health care expenditures, coverage by a complementary insurance, morbidity and socio-demographic characteristics such as age, social and occupational group and net income. The sample is composed of people living in regular households. Therefore, our study does not cover the field of long-term care, which concerns people living in nursing homes.

We will focus on three subgroups of expenditures: physician home and office visits, pharmaceutical expenditures related to ambulatory care, and hospital expenditures. Physician expenditures and pharmaceutical expenditures can easily be recorded individually by the public health insurance. However, prices are not observed as regards hospital care. Indeed, hospitals are mostly public in France. During the period under study, they are financed on the basis of a global budget payment system. Therefore, individual expenditures are not recorded as such: an assessment is implemented by the health insurance administration on the basis of the individual's recorded length of stay and of the average daily cost of stay in the corresponding care unit.

In order to make health care expenditures comparable between years 1992 and 2000, we had to adjust the observed expenditures for inflation and to convert all values to Euros. The price index ${ }^{5}$ is specific to the type of expenditure of interest. Between 1992 and 2000, the computed price index of physician consultations rose by $9.15 \%$, reflecting the changes in fee levels, which are mostly regulated. The price index of ambulatory pharmaceutical expenditures rose by $2.04 \%$. It does not reflect the price of innovations, which are not included in this index. The price index of hospital expenditures rose by $16.54 \%$. As for the pharmaceutical expenditures price index, it does not include technological progress. Indeed, the daily cost of stay in each care unit is computed on the basis of the use of doctors' and nurses' work (duration and intensity of care), together with a combination of the index of civil servants' wages and price index of regular goods.

Therefore, we simply adjust for the general inflation rate. The growth of adjusted health care expenditures we want to analyse is still influenced by the pace of technological progress, which we are precisely interested in.

3. Formerly CREDES, Research and Information Center for Health Economics, 10, rue Vauvenargues, 75018 Paris, France.

4. EPAS (i.e. Echantillon Permanent d'Assurés Sociaux), recorded by the French public health insurance of employed workers (CNAMTS), which covers about $83 \%$ of the population (Sandier et al., 2002).

5. Source: DREES and Ecosanté (IRDES, 2002). 

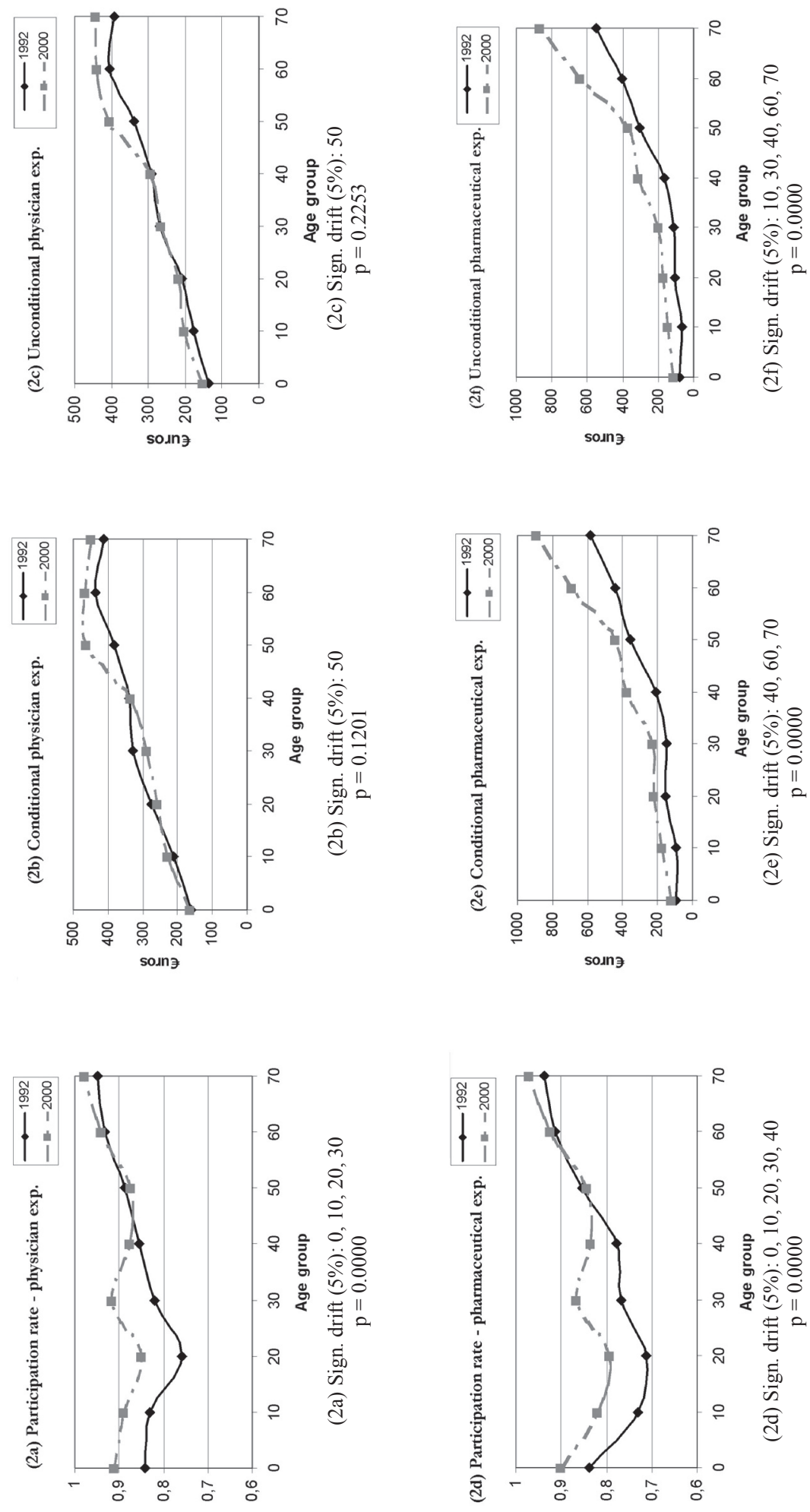

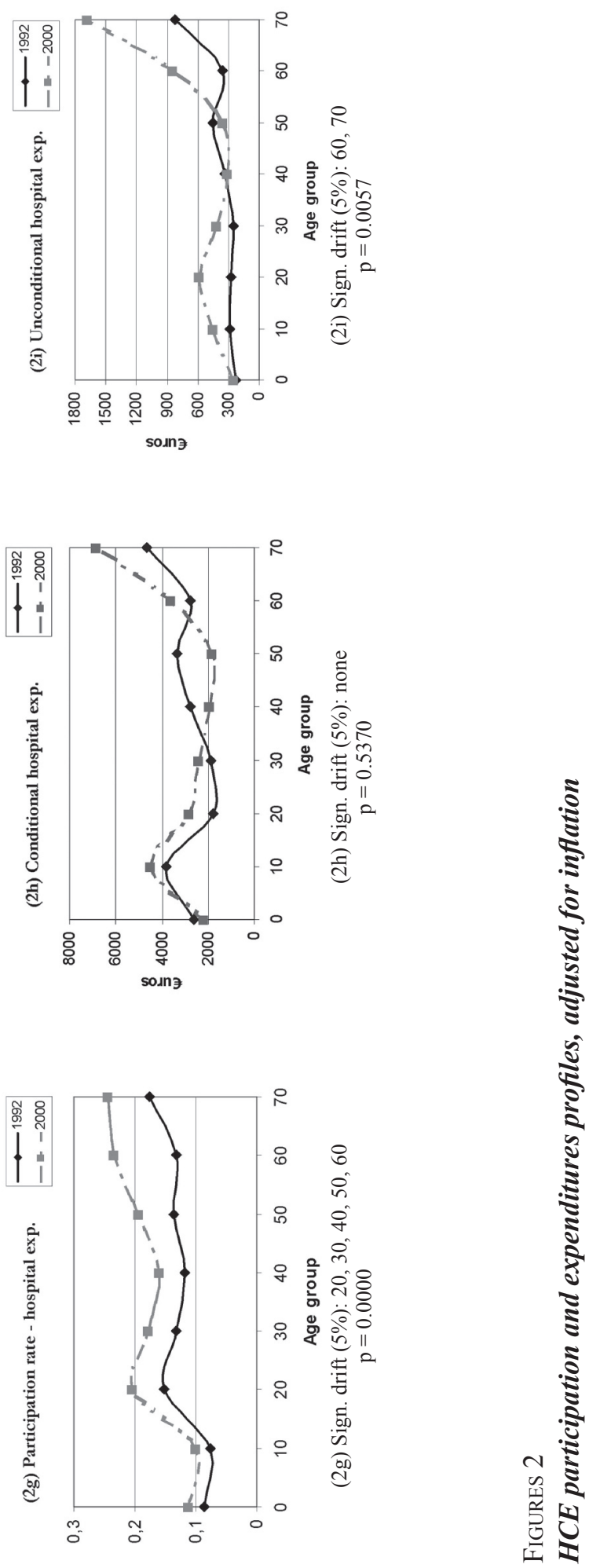


\subsection{Descriptive Analysis}

Table 1 presents the general characteristics of our sample. 3,441 individuals are observed in 1992 and 5,003 in 2000. The italics besides the percentages in the structure of health care expenditures studied refer to the corresponding proportions given for the whole population by the French Health Care Financing Administration. It can be seen that the overall proportion of each type of expenditure in our sample is relatively close to what is observed at the national level. Notice that we chose not to remove outliers from the data: indeed, removing the individuals who incurred the highest expenditures jeopardizes the representativity of each aggregate, particularly hospital expenditures.

TABLE 1

\section{Characteristics of the sample}

\begin{tabular}{|c|c|c|}
\hline & 1992 & 2000 \\
\hline $\mathrm{N}$ & 3441 & 5003 \\
\hline$\%$ women & $54,37 \%$ & $50,19 \%$ \\
\hline average HCE per capita (current euro) & 874,1 & 1386,81 \\
\hline participation rate & $86,60 \%$ & $92,14 \%$ \\
\hline \multicolumn{3}{|l|}{$\underline{\text { The structure of HCE }}$} \\
\hline proportion of physician's expenditures in studied HCE & $33,86 \%$ & $\begin{array}{c}25,81 \% \\
(22,5)\end{array}$ \\
\hline proportion of pharmaceutical expenditures in studied HCE & $23,23 \%$ & $\begin{array}{c}27,02 \% \\
(22,1)\end{array}$ \\
\hline proportion of hospital expenditures in studied HCE & $42,91 \%$ & $\begin{array}{c}47,17 \% \\
(41,5)\end{array}$ \\
\hline \multicolumn{3}{|l|}{$\underline{\text { Growth rate in HCE studied }}$} \\
\hline rise in physician expenditures (1992-2000) & & $\begin{array}{l}7,75 \% \\
(28,1)\end{array}$ \\
\hline rise in pharmaceutical expenditures (1992-2000) & & $\begin{array}{c}64,41 \% \\
(51,7)\end{array}$ \\
\hline rise in hospital expenditures (1992-2000) & & $\begin{array}{c}55,35 \% \\
(28,0)\end{array}$ \\
\hline
\end{tabular}

One feature of health data such as ours is that many individuals do not incur any expenditure. The level of expenditure is explained by the participation rate and by the conditional expenditure, conditional on participation. Figures $2 \mathrm{a}-\mathrm{i}$ show for each type of expenditure (physician visits, medication and hospital expenditures) the age profile of participation rate, conditional expenditure and unconditional expenditure. The participation rates of physician visits and pharmaceutical expenditures are quite high (around 90\%). The observed change in the participation 
profile has therefore a small impact on the unconditional expenditure. For these expenditures, the conditional and unconditional expenditures profiles are very similar (see figures $2 \mathrm{e}$ and $2 \mathrm{f}$ ). This is not the same for hospital expenditures, for which the participation rate is quite low (between $10 \%$ and $20 \%$ ): changes in the participation profile have a greater impact on the final profile, which shows a sizeable drift between 1992 and 2000 for people age 50 and over. These features show that ambulatory care and hospital care need separate analyses.

For physician and pharmaceutical expenditures, the profile (conditional and unconditional on participation) is clearly increasing with age. A noticeable upward drift of this profile appears for people age 40 and over between 1992 and 2000. The drift is spectacular and significant $(p<0.0001)$ for pharmaceutical expenditures, whereas it appears to be non significant $(p=0.22)$ for physician consultations ${ }^{6}$.

For hospital expenditures (conditional and unconditional), an upward drift is noticeable for people age 60 and over only (figure $2 \mathrm{i}$ ). Participation rate for hospital care has significantly increased between 1992 and 2000, for all age groups. This rise in participation explains the shape of the unconditional expenditures profiles: the corresponding drift is significant $(\mathrm{p}<0.0001$, due to age groups 60 and 70 and over) whereas the drift for conditional expenditures is not significant $(p=0.54)$.

The unconditional hospital expenditure figure might give support to the argument of Zweifel et al. and Seshamani et al., namely that proximity to death is the main driver of hospital costs. Indeed, the expenditure profile is relatively flat until the 50-59 age group, then becomes very sloping (figure 2i). Yang et al. show that the age profile of Medicare expenditures (which are mainly determined by hospital costs) is strongly influenced by the costs incurred by people who deceased within the year. Our data allowed us to compare, for year 2000, the expenditure age profiles of all individuals vs. individuals which were still alive in 2004 ("survivors"). We observe that the slope is less steep, but still sizeable for survivors: the shape of the hospital expenditures profile is not only due to the dying (Dormont et al., 2006).

\section{Morbidity and Age}

We have paid attention to the building and testing of relevant morbidity indicators. Indeed, the level of morbidity by age group and its changes over time play a central role in our empirical evaluation. Our dataset gives us access to detailed information about every individual's health status and the illnesses he/she might suffer from. In addition, information is recorded about the individual's characteristics and habits, such as his/her size, his/her body mass index (BMI), whether he/she is a regular smoker and about socioeconomic variables such as employment

6. We have implemented tests to check for the significance of the drifts observed in the profiles. Global significance tests have been carried out, as well as separate tests for each age group. Results are provided below figures $2 \mathrm{a}-\mathrm{i}$ : we give the age groups for which a significant drift is observed and the p-value of the global significance test. 
status (employed-unemployed-retired) and whether or not he/she receives allowances from the public assistance. None of these variables is used as a regressor in our equations of participation and consumption. Therefore they can be used as instrumental variables to test for the exogeneity of morbidity indicators.

The information at our disposal results from answers of the individual to the survey. Physicians check the survey and correct for discrepancies between objective information (e.g., type of medication taken) and declaration. Synthetic indicators have been built, such as the number of illnesses, the level of disability ( 8 levels) and the level of death risk. This latter variable is a grade given by the physicians who recode the survey, relative to the probability of death within the following five years. It has six levels, from 0 (zero death risk) to 5 (surely negative prognosis). In addition, we have built indicators for chronic diseases, such as Hypertension, Diabetes, etc (altogether 10 illnesses). All potential indicators are detailed in appendix A. The process of selection and testing is described in appendix B, leading to the indicators finally selected.

\subsection{Selecting Exogenous Morbidity Indicators}

If health care is effective, health status is not an exogenous regressor for medical expenditure. Logically, its exogeneity depends on the delay between expenditure and potential health improvements. The fact that our database is composed of 2 cross-sections relative to yearly expenditures has consequences on the regressors' exogeneity: chronic diseases are likely to be exogenous. Medical care cannot remove the cause but delay or prevent the consequences of these diseases. The most prevalent chronic diseases (diabetes, hypertension, or heart disease) cannot be cured and their onset is independent from the amount of medical care provided to the individual. On the other hand, procedures such as hip replacement improve substantially the patient's state: disability may be endogenous.

Most analyses of the impact of ageing on expenditures have included health status as a control in the relationship, without any way of testing whether the variables used to measure health status were exogenous. Thanks to the richness of our data, which make many instrumental variables available, we were able to perform exogeneity tests. For that purpose, we assumed that chronic diseases were exogenous. But the exogeneity of disability has been tested, as well as the exogeneity of synthetic indicators, such as death risk, self-assessed health and number of diseases. The procedure used is detailed in section 5 .

\subsection{Morbidity and Health Expenditures Profile}

It is well known that morbidity is increasing with age. This appears clearly in figures 3 , which display the average level by age group of 4 morbidity indicators.

A simple OLS analysis performed on untransformed data shows that the fact that health expenditures are increasing with age is entirely due to the increase in morbidity with age. Figure 4 presents the contribution of each one of 3 sets of variables explaining the level of conditional pharmaceutical expenditures in a basic untransformed linear model: age dummies, morbidity indicators and socio-economic characteristics (gender, income, coverage, social and occupational group, 
FigURES 3

\section{Changes in prevalence for four morbidity indicators}

Disability

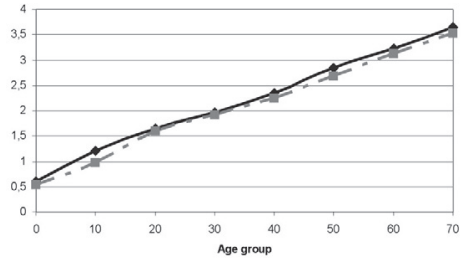

(3a) Disability

Diabetes

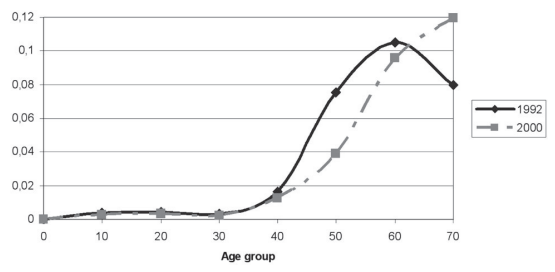

(3c) Diabetes
Vital risk

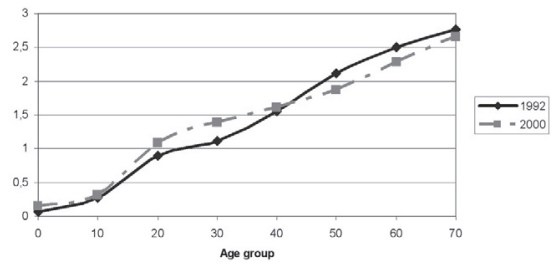

(3b) Death risk

Arthro-dorso

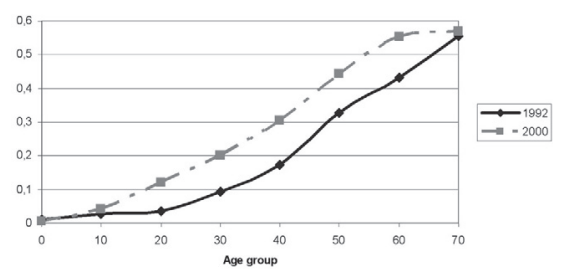

(3d) Arthritis, arthropathy and/or back pain

FiguRE 4

Effects of different predictors of HCE (drugs, year 1992)

\section{OLS decomposition of pharmaceutical expenditures, 2000}

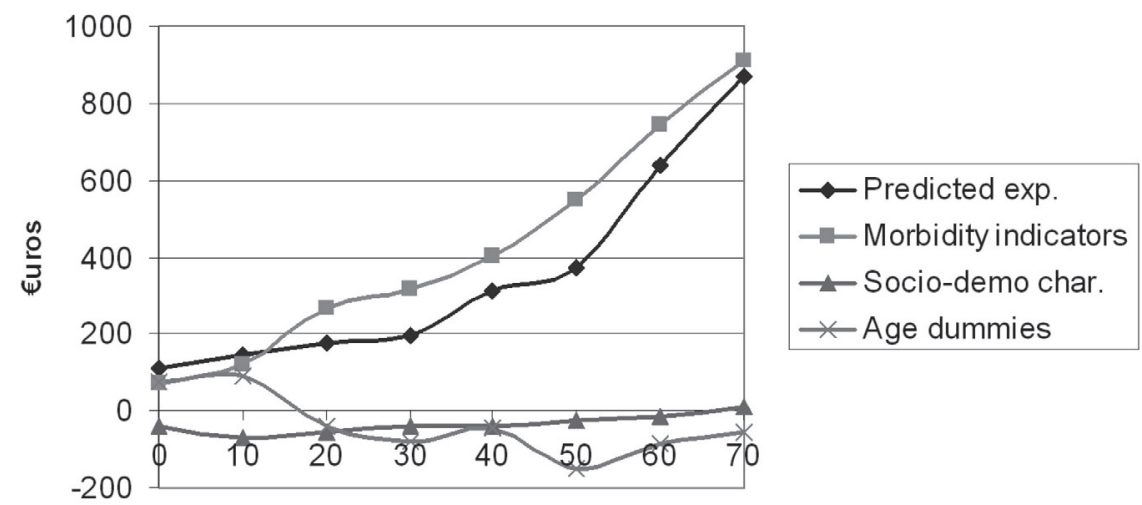

Age group

level of education $)^{7}$. The figure shows clearly that age dummies do not influence the expenditure profile, once morbidity in taken into account.

7. This was obtained for the year 2000. Comparable graphs can be obtained for the year 1992 and other types of expenditures. The same kind of results has been obtained as regards participation rate: the increasing profile of the use of health care services with age is mainly explained by the evolution of morbidity with age. 


\subsection{Changes in Morbidity Over Time}

Figures 3 illustrate the changes in morbidity by age profiles that occurred between 1992 and 2000. These graphs are representative of what is found for our various indicators. For most of them, there is a decrease in the level of morbidity over time, i.e. a health improvement. However, this is not systematic and not homogenous among age groups. For instance, the frequency of diabetes is decreasing for all age groups between 1992 and 2000, but increases for individuals aged 70 and over (figure $3 \mathrm{c}$ ). On the other hand, the frequency of arthritis and back pain is increasing for each age group (figure $3 \mathrm{~d}$ ).

These results do not allow to draw any general conclusion about a health improvement hypothesis: the prevalence is increasing or decreasing, depending on the morbidity indicator and the age group considered. Our estimation approach allows us to evaluate the resulting effect of all these changes on expenditure by age group. In other words, it is possible to synthesize the total impact of changes in morbidity. Anticipating on our results, we find that this impact is negative, indicating that the health status of individuals is improving, indeed.

\section{The Empirical Approach}

The purpose of our simulations is to examine the influence of various effects on the shifts in the age-profile of health expenditures. Our empirical approach entails three steps: firstly, the specification and estimation of a two-equations model explaining the decision to consume and the level of expenditure, conditional on participation; secondly, the use of the estimates to simulate counterfactual average levels of participation and expenditure by age group. This second step makes it possible to assess the impacts of changes in morbidity and changes in practices between 1992 and 2000. In the third step, we use the microsimulation results to evaluate, at the macroeconomic level, the respective effects of demographic changes (ageing) and profile drifts (changes in morbidity and practices) on health expenditure growth.

This approach is implemented for each of the three components of health care expenditure we focus on: physician consultations, pharmaceutical consumption, hospital expenditures.

\subsection{Econometric Specifications and Estimation}

A typical feature of health expenditure data is that many individuals incur no health costs within the period of observation. The descriptive analysis has shown the high proportion of non-users for hospital. As regards consultations and drugs, the proportion of non-users, although smaller, is not negligible. Such a configuration requires specific estimation techniques. Many papers addressed the issue of the choice between the sample-selection model (Heckman, 1979) and the two-part 
model (Dow et al., 2002; Leung et al., 1996; Manning et al., 1987). Monte Carlo studies implemented by Manning, Duan and Rogers show that the two-part model performs better than the sample selection model even when the latter is the true model. Leung and Yu have shown that the performances of the sample selection model depend crucially on the degree of collinearity between the inverse Mill's ratio and the explanatory variables in the second step equation. When there is no collinearity, a t-test of the coefficient of the inverse Mill's ratio can be used to choose between the two specifications. On the other hand, collinearity problems make the two-part model more reliable because it performs better in terms of meansquared error than the sample-selection model.

Our data is characterized by a high correlation between the inverse Mill's ratio and the explanatory variables of the second step equation: the correlation coefficient lies between 0.85 and 0.87 , depending on the health expenditure component considered. Therefore, we chose the two-part model, which presents another advantage: it permits the use of a generalized linear model (GLM) to estimate the level of consumption, conditional on participation. The GLM makes it possible to deal rather easily with other typical features of health consumption data, such as skewness in the raw-scale variable, heavy-tailed distributions and heteroscedastic errors. Indeed, the GLM approach makes it possible (i) to avoid the retransformation difficulties ${ }^{8}$ by specifying directly the expectancy of expenditure instead of the $\log$ of expenditure, (ii) to allow for heavy-tailed distributions and heteroscedastic errors by considering Poisson or Gamma distributions for the dependent variable (Manning et al., 2001).

Consider individual $i$ belonging to age group $j$. We denote $P_{i j}$ the dichotomic variable for participation and $C_{i j}$ the health care consumption and consider the following model:

$$
P_{i j}=\mathbf{I}_{P_{i j}^{*}>0} \text { with } P_{i j}^{*}=W_{i j}^{\prime} c+M_{i j}^{\prime} b+a_{j}+u_{i j}=X_{1, i j}^{\prime} d+u_{i j},
$$

where $u_{i j} \sim N\left(0, \sigma^{2}\right)$.

$$
\left\{\begin{array}{l}
C_{i j}=\mathrm{I}_{\left(P_{i j=1}\right)}\left[C_{i j}^{*}\right] \\
\text { with } E\left(C_{i j}^{*} \mid X_{2, i j}^{\prime}\right)=\exp \left(Z_{i j}^{\prime} \gamma+M_{i j}^{\prime} \beta+\alpha_{j}\right)=\exp \left(X_{2, i j}^{\prime} \delta\right)
\end{array}\right.
$$

We decided to use for (2) a log link relationship: $E\left(C_{i j}^{*} \mid X_{2, i j}^{\prime}\right)$ is defined as an exponential function of $X_{2, i j}^{\prime} \delta$. Indeed, the non-zero observations for health expenditures are highly skewed (the skewness varies between 4.50 and 15.47, depending on the year and type of expenditure considered). Taking the log transformation reduces the skewness to values between -0.26 to 0.01 . In addition, we used for $C_{i j}^{*}$ a gamma distribution, which enables us to take heteroskedasticity into account.

8. In the case of a $\log$ linear specification, where $\log (y)=x \beta+u$, predicting $\mathrm{y}$ on the untransformed scale is not so easy because $E(y \mid x)=E[\exp (x \beta+u) \mid x]$. This latter expression is proportional to $\exp (x \beta)$ only under restrictive assumptions as regards the distribution of $u$ (Manning et al., 2001). 
The choice of a gamma distribution is based on the outcomes of Park tests that we have performed, following the approach suggested by Manning and Mullah.

Equation (1) describes the decision to use health care services and equation (2) the level of consumption.

$X_{1, i j}^{\prime}$ and $X_{2, i j}^{\prime}$ are the explanatory variables of the participation and consumption equations. These regressors entail dummies $a_{j}$ and $\alpha_{j}$ related to the age groups and morbidity indicators $M_{i j}^{\prime}$. In addition, equations (1) and (2) include explanatory variables (variables $W_{i j}^{\prime}$ or $Z_{i j}^{\prime}$ ) relative to socio-economic characteristics of the individual. The potential list of morbidity indicators include disability, death risk, the number of illnesses, self-assessed health, and indicators for the following illnesses: diabetes, chronic obstructive pulmonary disease and related diseases, ischemic heart disease, hypertension, circulatory disease, conditions associated with lipid metabolism, depression, sleeping disorder, cataract, and arthritis, arthropathy and/or back pain. The potential list of socio-economic characteristics include level of earnings, social and occupational group, education level, coverage by a complementary insurance, gender, family size and matrimonial status. The effective list depends on the equation ((1) or (2)) and on the type of expenditure considered (physicians, pharmaceutical or hospital): it has been set by a careful selection process described in appendix B.

As stated in section 3, some morbidity indicators may be non exogenous. Chronic diseases are likely to be exogenous. On the other hand, disability and synthetic indicators of health status, such as death risk, self-assessed health and number of diseases may be non exogenous. In addition, the coverage by a complementary insurance may be non exogenous, since it results partly from an individual decision. We have chosen to select only exogenous regressors to avoid adding methodological difficulties to an already rather sophisticated approach.

Thanks to the richness of our data, we were able to perform Hausman tests for consultations, pharmaceutical and hospital expenditures. This was possible for year 2000 only. Not enough instruments were available for 1992, where the survey did not record enough information about socioeconomic variables nor about individual characteristics and habits. Nevertheless, it seems to us legitimate to assume that exogeneity checked for 2000 holds for 1992.

We used intrumental variables to build a Hausman specification test for each of the three types of health care consumption, following Rivers and Vuong's (1988) approach for the participation equation and using a log-linear model for the consumption equation. A Sargan test was used to check the validity of the instruments used. In addition, we examined whether this test could be subject to the weak instrument problem (Staiger and Stock, 1997). For this purpose, we tested for global significance of the instruments in a system equation model (Seemingly Unrelated Regressions [SUR]) comprising several equations, where each instrumented variable is explained by the instruments and the exogenous regressors. Detailed list of intruments used and outcomes of the tests are provided in appendix B. We found a large significance of the partial correlation between instruments and morbidity indicators, with high statistics and levels of significance lower than $10^{-3}$. Sargan tests validated the exogeneity of the instruments. Coverage by a complementary insurance appear to be exogenous for consultations and pharmaceutical expenditures (it is not a significant regressor for hospital). Exogeneity is rejected for disability as regards consultations expenditures and for death risk as regards pharmaceutical expenditures. 


\subsection{Predictions and Simulations}

For individual $i$ of age group $j$, the decision to use health care services is easily predicted from the estimation of (1) by a Probit estimator:

$$
\hat{E}\left(P_{i j} \mid X_{1, i j}\right)=\Phi\left(X_{1, i j}^{\prime} \hat{d}\right)
$$

with $\Phi($.$) standing for the cdf of the standard normal distribution.$

As concerns conditional expenditures, the GLM specification leads to a direct estimate of the conditional expectancy of expenditures on the raw scale:

$$
\hat{E}\left(C_{i j} \mid P_{i j}=1 ; X_{2, i j}\right)=\exp \left(X_{2, i j}^{\prime} \hat{\delta}\right)
$$

The model is estimated separately for years 1992 and 2000 for each type of expenditures (consultations, pharmaceutical, hospital), leading to estimated coefficients $\hat{d}_{92}, \hat{d}_{00}, \hat{\delta}_{92}$ and $\hat{\delta}_{00}$

Since the computation of predictors (3) and (4) involve several non-linear functions, we cannot exhibit additive effects. We use instead an incremental approach. As concerns the decision to use health care services (participation), we compute or simulate the predicted probability for the average patient of each age group $j$. This is done for each expenditure component, i.e. physician visits, drugs and hospital.

For the population observed in 1992, the predicted probability of using health care services is the following:

$$
\hat{\pi}_{i j}^{92.92}=\Phi\left(X_{1, i j}^{\prime 92} \hat{d}_{92}\right)=\Phi\left(W_{1, i j}^{\prime 92} \hat{c}_{92}+M_{i j}^{\prime 92} \hat{b}_{92}+\hat{a}_{j, 92}\right)
$$

This probability is evaluated at the average point of each age group:

$$
\hat{\pi}_{. j}^{92.92}=\Phi\left(X_{1, . j}^{\prime 92} \hat{d}_{92}\right)=\Phi\left(W_{1, . j}^{\prime 92} \hat{c}_{92}+M_{. j}^{\prime 92} \hat{b}_{92}+\hat{a}_{j, 92}\right)
$$

We have chosen this approach instead of computing the average by age group of individual predicted probabilities. Indeed, counterfactual simulations on population characteristics are possible at the age group level only.

The effect on participation of changes in practices for a given morbidity is assessed by replacing $\hat{b}_{92}$ by $\hat{b}_{00}$ in expression (5):

$$
\hat{\pi}_{. j}^{m 92 . b 00}=\Phi\left(W_{1, . j}^{\prime 92} \hat{c}_{92}+M_{. j}^{\prime 92} \hat{b}_{00}+\hat{a}_{j, 92}\right)
$$


The incremental effect of changes in morbidity between 1992 and 2000 is assessed by replacing, for each age group, the average level of morbidity observed in $1992, M_{. j}^{\prime 92}$ by the average level of morbidity observed in 2000, $M_{. j}^{\prime 00}$ :

$$
\hat{\pi}_{. j}^{m 00 . b 00}=\Phi\left(W_{1, . j}^{\prime 92} \hat{c}_{92}+M_{. j}^{\prime 00} \hat{b}_{00}+\hat{a}_{j, 92}\right)
$$

Finally, the incremental effects of other changes in behavior and individual characteristics lead to the predicted probability for the year 2000:

$$
\hat{\pi}_{. j}^{00.00}=\Phi\left(X_{1, . j}^{\prime 00} \hat{d}_{00}\right)=\Phi\left(W_{1, . j}^{\prime 00} \hat{c}_{00}+M_{. j}^{\prime 00} \hat{b}_{00}+\hat{a}_{j, 00}\right)
$$

We used expression (4) to compute similarly the predictions of the levels of expenditures by age group, conditional on participation: $(C \mid P)_{. j}^{92.92},(C \mid P)_{. j}^{m 92 . b 00}$, $(C \mid P)_{. j}^{m 00 . b 00}$ and $(C \mid P)_{. j}^{00.00}$. More precisely, the means by age group of the explanatory variables are computed on the subsamples of participants, when simulating the conditional expenditures. We have the following transitions:

- The transition from $(C \mid P)_{. j}^{92.92}$ to $(C \mid P)_{. j}^{m 92 . b 00}$ gives the effect of changes in practices for a given morbidity.

- The transition from $(C \mid P)_{. j}^{m 92 . b 00}$ to $(C \mid P)_{. j}^{m 00.600}$ gives the incremental effect of changes in morbidity (among the participants) between 1992 and 2000.

- Finally, the transition from $(C \mid P)_{. j}^{m 00 . b 00}$ to $(C \mid P)_{. j}^{00.00}$ gives the incremental effect of other changes of behavior and individual characteristics between 1992 and 2000 .

At each step, unconditional expenditure $C$ is computed as the product $\pi *(C \mid P)$.

Broadly understood, changes in practices are changes in the estimated parameters of (1) or (2) between 1992 and 2000. These changes are linked to changes in patients' or physicians' behavior. They also result from technological progress, which induces the use of more costly innovative drugs and procedures. As explained in section 2.1, this technological progress may concern the extension of innovative procedures and prevention protocols to old ages.

We capture changes in practices for a given morbidity with changes in the estimated vectors $\hat{b}$ and $\hat{\beta}$. These estimated coefficients measure the influence of morbidity on participation rate and expenditures. What we call "other changes in behavior and individual characteristics between 1992 and 2000" can also be interpreted as changes in practices. Actually, these "other changes" depend on changes in the variables $W$ and $Z$, as well as changes in the parameters $\hat{c}, \hat{\gamma}, \hat{a}_{j}$ and $\hat{\alpha}_{j}$. To make the graphs relative to the micro simulations readable, we did not present separately the effects of changes in the age-specific constants. But this is done in the recapitulative table of 
section 6, where we make the evaluations at the macroeconomic level. These changes in age-specific constants can be linked to changes in unobservable morbidity as well as changes in practices for a given level of morbidity.

Our microsimulation method is in the spirit of the Oaxaca (Oaxaca, 1973) methodology. It has been recently used to analyse the process of technological progress diffusion within French hospitals (Dormont et al., 2006).

\section{Microeconometric Results}

\subsection{Estimations}

As was mentioned in section 4, the variables explaining participation and conditional expenditure were carefully selected. Only those that proved to be significant and exogenous were kept for the estimations and simulations.

The estimation of equations (1) and (2) reveals a strong influence of morbidity on participation and conditional consumption ${ }^{9}$. The morbidity indicators, the number of diseases and the levels of disability and death risk have large positive impacts on the use of health care services. To take an example, in 1992, a disability level ${ }^{10}$ equal to 3 incurs an increase in conditional pharmaceutical consumption of $42 \%$. When the disability leve $\mathrm{l}^{11}$ is equal to 4 or 5 , the rise in the conditional pharmaceutical consumption amounts to $77 \%$ and $89 \%$. The conditional pharmaceutical consumption is also strongly influenced by hypertension $(+40 \%)$, diabetes $(+48 \%)$ trouble with lipid metabolism $(+25 \%)$ and depression $(+37 \%)^{12}$. Participations to consultation and pharmaceutical consumption are also significantly influenced by our morbidity indicators. The conditional consultation expenditure is positively influenced by depression $(+27 \%)$ and the number of diseases. Turning to hospital expenditure, participation appears to be positively influenced by diabetes, death risk and cataract, and the level of conditional expenditure by the level of disability and hypertension $(+37 \%)$.

Otherwise, we find that the absence of privately subscribed complementary coverage significantly reduces participation and consumption of ambulatory care. For example, in 1992, the drop amounts to $-39 \%$ for conditional physician expenditures and to $-25 \%$ for conditional pharmaceutical expenditures. On the other hand, complementary coverage has no significant influence on the use of hospital care. In general, gender is not significant for participation, but being a female increases consultation and pharmaceutical expenditures by about $17 \%$. Gender is not significant for hospital expenditures.

9. We do not display the detailed results here. They are available on request.

10. Disability level 3 corresponds to a situation where the individual "experiences difficulties but lives normally".

11. Disability level 4 corresponds to a situation where the individual "must diminish his/her domestic or professional activity". Level 5 encompasses situations as "diminished activity", "no domestic autonomy" and "confined to bed".

12. These figures are given for the 1992 estimates. 
Most of the positive coefficients estimated for the morbidity indicators in 1992 are larger in 2000 . It clearly shows that changes in practices result in more expenditures in 2000 than in 1992, for a given morbidity.

\subsection{Simulations}

The simulations we implemented led to the calculation of average probabilities of participation and conditional expenditures for each age group $j$, at each step of the reasoning. Namely, the values $\hat{\pi}_{. j}^{92.92}, \hat{\pi}_{. j}^{m 92 . b 00}, \wedge^{m 00 . b 00}$ and $\hat{\pi}_{. j}^{00.00}$ were computed for participation and $(C \mid P)_{. j}^{92.92},(C \mid P)_{. j}^{m 92 . b 00},(C \mid P)_{. j}^{m 00.600}$ and $(C \mid P)_{. j}^{00.00}$ for the conditional expenditures. At each step of simulation, unconditional expenditure $C$ is computed as the product $\pi *(C \mid P)$. The resulting profiles by age group are displayed in figures 5a-i. For each variable of interest, the drift between the profile of 1992 (profile 1) and the profile of 2000 (profile 4) is split into 3 incremental effects: $(i)$ the transition from profile 1 to profile 2 gives the effect of changes in practices for a given observable level of morbidity; $(i i)$ the transition from profile 2 to profile 3 gives the effect of changes in morbidity; (iii) the transition from profile 3 to profile 4 gives the effect of other changes in behavior and individual characteristics. Ambulatory care (physician and pharmaceutical expenditures) and hospital expenditures show fairly different results, which are worth treating separately.

Figure 5F (ZOOMED)

\section{Simulated unconditional pharmaceutical expenditures}

Simulated unconditional pharmaceutical exp.

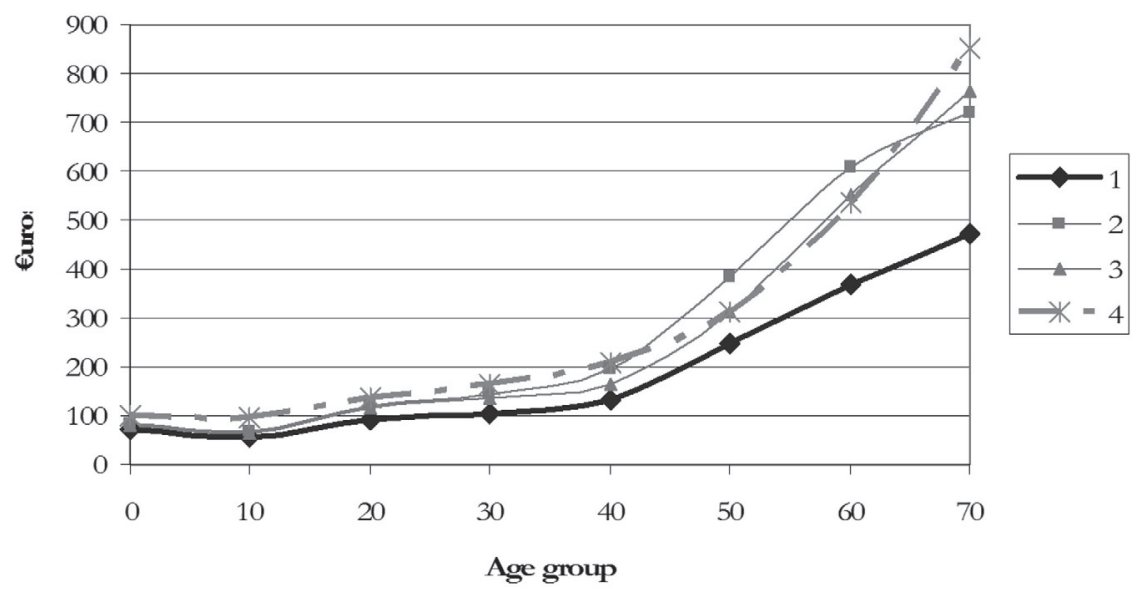


Figure 5i (ZOOMED):

\section{Simulated unconditional hospital expenditures}

Simulated unconditional hospital exp.

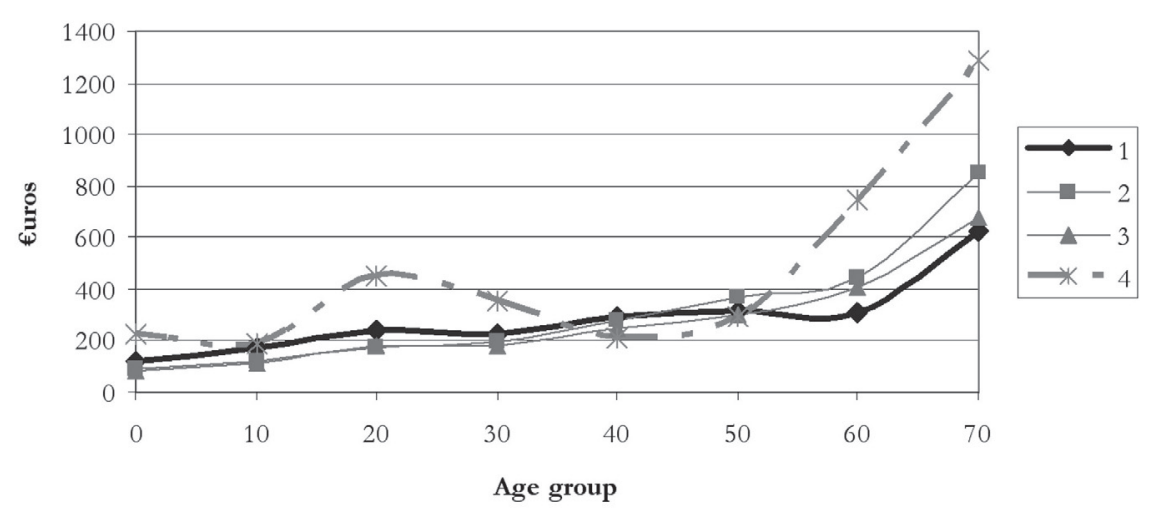

Profile 1: predicted expenditure, 1992. Profile 2: expenditure with population characteristics of 1992 and morbidity coefficients of 2000 (counterfactual simulation). Profile 3: expenditure with population characteristics of 1992, morbidity coefficients of 2000 and morbidity level of 2000 (counterfactual simulation). Profile 4: predicted expenditure, 2000.

Transition 1 to 2: drift due to changes in practices for a given morbidity level. Transition 2 to 3 : incremental drift due to changes in morbidity. Transition 3 to 4 : incremental drift due to other changes.

\subsubsection{Ambulatory Care}

For ambulatory care, the bulk of changes is essentially due to changes in expenditures conditional on participation and not to changes in participation. Changes in participation rate have a very small influence on unconditional expenditures profile drifts. Indeed, participation to ambulatory care is already very high in 1992 (between $80 \%$ and 98\%): changes that occurred in 2000 are necessarily limited.

The drift in the age profile of expenditures is much more spectacular for pharmaceutical expenditures than for physician consultations, whose drift is globally non significant ${ }^{13}$. This appears when comparing figures $5 \mathrm{c}$ and $5 \mathrm{f}$, keeping in mind that scales differ.

As concerns physician expenditures, one observes a small negative drift due to changes in practices (figure 5c, profile 1 to 2): for a given illness, less consultations are used in 2000 than in 1992. A positive drift, which is mainly due to "other changes" offsets this negative impact: on the whole, changes between 1992 and 2000 are not significant as regards physician expenditures.

Drugs are responsible for the bulk of the growth in total health care expenditures. The pharmaceutical expenditures rise tremendously: the changes are clearly observable in the zoomed figure 5 f. Our simulations show that this growth is almost entirely due to a large upward drift in relation to changes in practices for a given observable level of morbidity (profile 1 to 2 ). The changes in morbidity induce a downward drift which compensates only partly this upward drift. Our results suggest that there is a large innovation component: the drift is not due to changes in

13. See tests in figure $2 \mathrm{~b}$ and $2 \mathrm{c}$. 

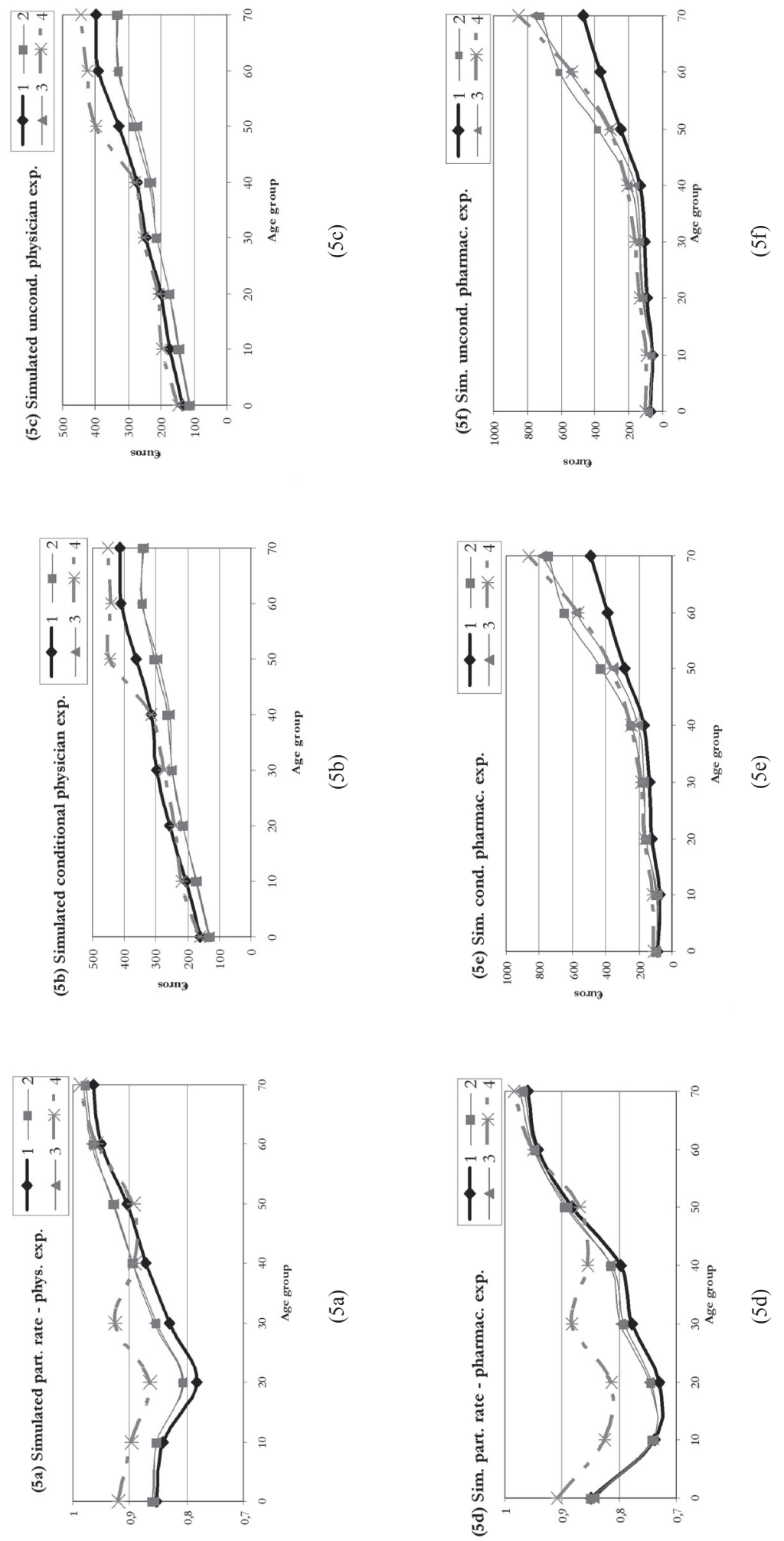

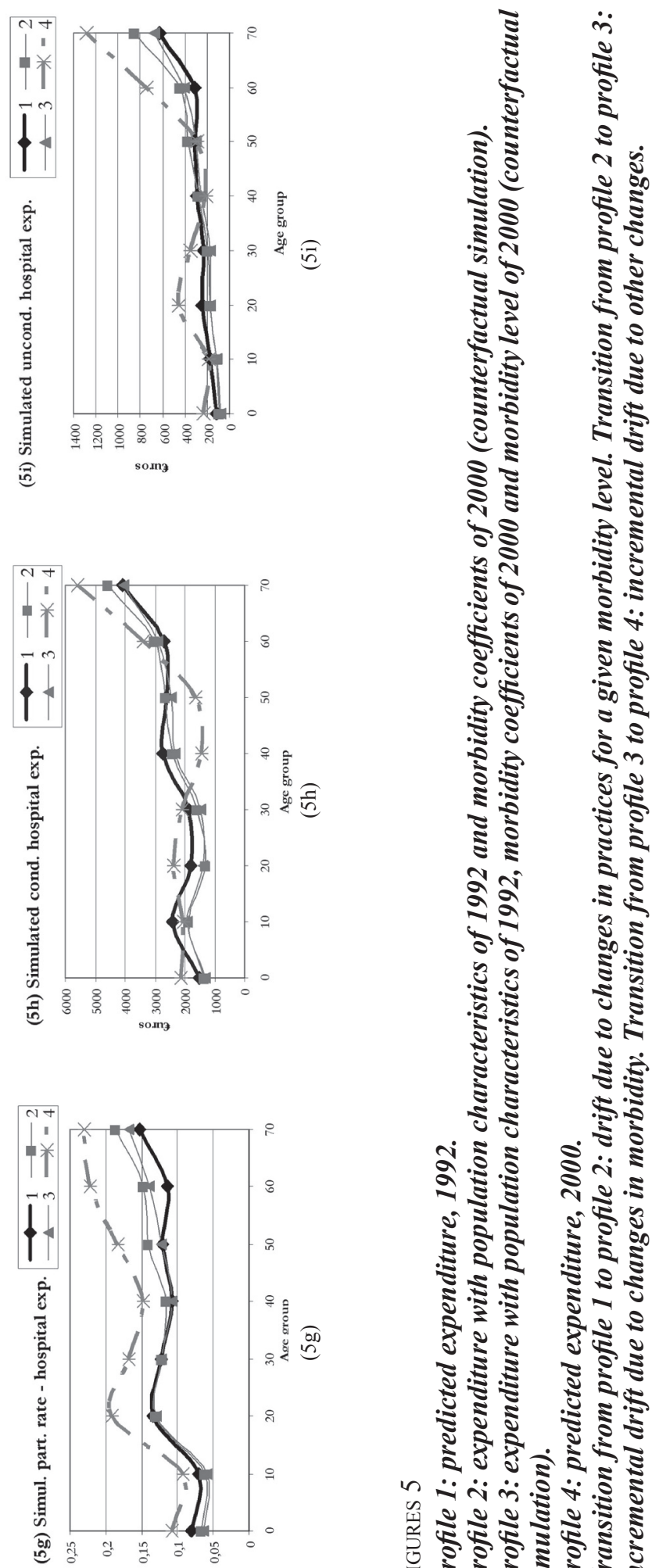

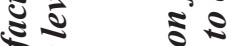

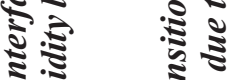

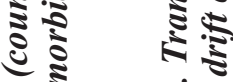

จ

ปิ

ปิ

范

范

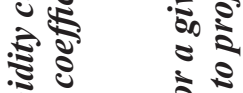

i.

ป⿱艹

ป ป

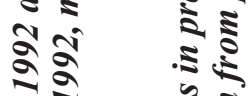

रु के के है

㺼.

约 8

ป气

告

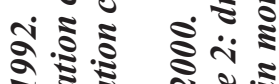

ชิ ปี

ㄱำ

2.5.

ㄱ․ำ.

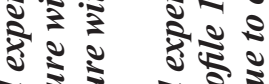
ว. ㄱำ

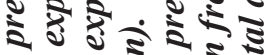

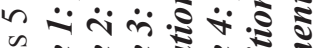

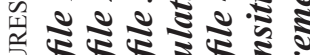

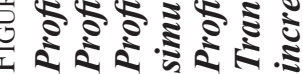


the behaviour of the elderly, but is rather linked to the supply of new products on the health care market.

\subsubsection{Hospital}

What is observed for hospital care contrasts strongly with ambulatory care, in the sense that changes are mainly due to a drift in the participation profile by age (see figure $5 \mathrm{~g}$ ). The drift in participation rates is observed for every age group and is increasing with age. Our simulation shows that this upward drift is due firstly to the "other changes" and secondly to changes in practices for a given level of morbidity. The upward drift due to the changes in practices (profile 1 to 2 ) is noticeable for the more than 50 year-olds, along with a slight downward drift due to the changes in morbidity for these same age groups.

As for hospital unconditional expenditures, we find again the negative effect of changes in morbidity for people age 40 and over, as well as the positive effect of changes in practices for a given morbidity. One observes for the two last age groups a tremendous drift due to the combined effects of changes in practices and "other changes". This jump is only visible on figure $5 \mathrm{i}$ (unconditional expenditures), since it stems from the changes in participation behaviour.

\section{Accounting for the Effects of Ageing and Changes in Practices at the Macro Level}

On table 2, we applied the predictions and simulations derived above to the French population. This allows us to evaluate retrospectively the relative effects of the demographic change and profile drifts that occurred between 1992 and 2000. In addition, we can evaluate the components of changes in profile drifts.

The total demographic effect is computed assuming that the 1992 age profile of expenditures is held constant, and that only the structure and size of the population changed over time. The other effects are then computed by using the different simulated profiles. A bootstrap analysis has been performed to assess the significancy of these results (bootstrap by pairs, 800 replications).

We find again the negative effect of changes in morbidity. The rise in health care expenditures due to the demographic change appears to be very small, in comparison with the effects of changes in practices. For total expenditures, we find that the impact of changes in practices is equal to $+12.9 \%$. Thus, it is 3.8 times larger than the rise in health care expenditures due to changes in the age structure of the population $(+3.4 \%)$. Moreover, we find that the impact of changes in morbidity is negative, indicating an improvement of the health status of individuals for a given age. This is true for total expenditure but also for each type of expenditure. For total expenditure, this negative effect of changes in morbidity $(-9.7 \%)$ more than compensates the positive shock due to changes in the age structure of the population $(+3.4 \%)$. This is also true for pharmaceutical and hospital expenditures. Drawing a rapid conclusion, one could ask whether the population is ageing at all. 
TABLE 2

\section{Simulations at the macro level}

\begin{tabular}{rcccc}
\hline \hline Variation 1992-2000 (\%) & Physicians & Pharmac. & Hospital & Total \\
\hline $\begin{array}{r}\text { of which: } \\
\text { Total demographic change }\end{array}$ & 5,05 & 7,63 & 6,37 & 6,35 \\
part of structural change & 2,10 & 4,61 & 3,38 & 3,36 \\
part of growing size & & & & \\
of population & 2,95 & 3,02 & 2,99 & 2,99 \\
\hline $\begin{array}{r}\text { Changes in practices for a } \\
\text { given morbidity }\end{array}$ & $-15,09$ & 52,24 & 7,06 & 12,87 \\
$\begin{array}{r}\text { Changes in morbidity } \\
\text { Changes in age dummies }\end{array}$ & $-1,23$ & $-9,24$ & $-14,61$ & $-9,74$ \\
Other changes & $-2,80$ & 14,11 & $-26,25$ & $-1,55$ \\
\hline Total variation 1992-2000 (\%) & 14,57 & 67,27 & 68,08 & 53,89 \\
\hline
\end{tabular}

\section{Conclusion}

Our results show that ageing is likely to explain only partially the rise in health care expenditures. The main explanation of expenditure growth is linked to changes in practices. For ambulatory care, changes in practices for the elderly are not linked to changes in participation behaviour but to changes in conditional consumption. The drift due to changes in practices is spectacular for pharmaceutical expenditures, suggesting a large innovation component. These results reveal that the drifts we observe are not due to changes in the behaviour of the elderly. They are connected rather to the supply side, that is, to the introduction of new products on the health care market. Our study is not restricted to hospital expenditures. Indeed, our data allow us to split health care expenditures into three components: physician, pharmaceutical and hospital expenditures. Because we were able to consider pharmaceutical expenditures separately, we were able to show that the upward drift in drug consumption is mainly due to the supply of new products, i.e. to technological progress. Taking participation into account in our model allowed us to isolate changes that might be due to patients' initiative. Our results suggest that they are of little importance.

Another advantage of our database is that it provides information about morbidity indicators. This enabled us: $(i)$ to show that the health of the elderly is improving $(i i)$ to evaluate the savings due to changes in morbidity. Health care expenditures are too often conceived of as a burden and it is indeed very difficult to measure their benefit in terms of health improvement. Our findings give evidence of health improvements.

We have shown that changes in practices appear to be the main driver in the increase in expenditures. It is possible that technological progress is oriented towards the elderly more than other age groups. In that case, the impact of changes 
in practices would increase with age. Due to our data limitations, we were not able to estimate slopes specific to each age group in order to study this question. Further investigation with larger samples will allow us to study the pattern of technological progress diffusion more thoroughly.

\section{References}

BaC C. and Cornilleau G. (2002). - « Comparaison internationale des dépenses de santé : une analyse des évolutions dans sept pays depuis 1970. » Etudes et Résultats, DREES, 175.

Baubeau D., Bousquet F. and Joubert M. (2001). - « Le traitement chirurgical de la cataracte en France », Etudes et Résultats, DREES, 101, 2001.

Dormont B., Grignon M. and Huber H. (2006). - "Health Expenditure Growth: Reassessing the Threat of Aging", Health Economics, 15: pp. 947-963.

Dormont B., and Milcent C. (2006) «Innovation Diffusion under Budget Constraints., Annales d'Economie et de Statistique, $\mathrm{n}^{\circ}$ 79/80.

Dow W.H. and NoRTON E.C. - "The Red Herring that Eats Cake: Heckit Versus Two-Part Model Redux", February 2002. Triangle Health Economics Working Paper Series - www.unc.edu/the.

Gerdtham U.G., Jonsson B., MacFarlan M. and Oxley H. (1998). - Health, the Medical Profession and Regulation, chapter "The Determinants of Health Expenditure in the OECD Countries: a Pooled Data Analysis", pages 113-134. Kluwer Academic Publisher.

Gerdtham U.G., Sogaard J., Andersson F. and Jonsson B. (1992). - "An Econometric Analysis of Health Care Expenditure: a Cross-Section Study of the OECD Countries", Journal of Health Economics, 11, pp. 63-84.

Getzen T.E. (1992). - "Population Aging and the Growth of Health Care Expenditures", Journal of Gerontology, 47: pp. S98-S104.

Heckman J.J. (1979). - "Sample Selection Bias as a Specification Error", Econometrica, 47:153-161.

HitiRis T. and PosnetT J. (1992). - "The Determinants and Effects of Health Expenditure in Developed Countries”, Journal of Health Economics, 11:173-181.

IRDES Institute Paris France. Eco-Santé 2002 Database.

Leu R.E. (1986). - Public and Private Health Services: Complementarities and Conflicts, Chapter "The Public-Private Mix and International Health Care Costs", pp. 41-63. Blackwell Scientific Publications.

Leung S.F. and Yu S. (1996). - "On the Choice Between Sample Selection and Two-Part Models", Journal of Econometrics, 72: pp. 197-229.

Manning W., Duan N. and Rogers W. (1987). - "Monte Carlo Evidence on the Choice Between Sample Selection and Two-Part Models", Journal of Econometrics, 35: pp. 59-82.

Manning W.G. and Mullahy J. (2001). - "Estimating Log Models: to Transform or not to Transform?", Journal of Health Economics, 20: pp. 461-494.

OAXACA R. (1973) "Male-Female Wage Differentials in Urban Labor Markets", International Economic Review, 14 : pp. 693-709

O'Connell J. (1996). - "The Relationship Between Health Expenditures and the Age Structure of the Population in OECD Countries", Health Economics, 5: pp. 573-578.

Oberlin Ph., Mouquet M.-C. and Folliguet Th. (february 2004). - « Le traitement invasif des maladies coronariennes », Etudes et Résultats, DREES, 289.

OECD (1987). - Financing and Delivering Health Care: a Comparative Analysis of OECD Countries.

Rivers D. and Vuong Q. (1988). - "Limited Information Estimation and Exogeneity Tests for Simultaneous Probit Models", Journal of Econometrics, 39: pp. 347-366.

Sandier S., Polton D., Paris V. and Thomson S. (2002). - Health Care Systems in Eight Countries: Trends and Challenges, chapter "France", pp. 31-45. The European Observatory on Health Care Systems.

Seshamani M. and Gray A.M. (2004a). - "A Longitudinal Study of the Effects of Age and Time to Death on Hospital Costs", Journal of Health Economics, 23: pp. 217-235. 
Seshamani M. and Gray A.M. (2004b). - "Aging and Health-Care Expenditure: the Red Herring Argument Revisited", Health Economics, 13: pp. 303-314.

StAiger D. and Stock J.H (1997). - "Instrumental Variables Regression with Weak Instruments", Econometrica, 65: pp. 557-586.

Stearns S.C. and Norton E.C. (2004). - "Time to Include Time to Death? the Future of Health Care Expenditure Predictions", Health Economics, 13: pp. 315-327.

Yang Z., Norton E.C. and Stearns S.C (2003). - "The Real Reasons Older People Spend More", Journal of Gerontology: Social Sciences, 58B(1): pp. S1-S10.

Zweifel P., Felder S. and Meiers M. (1999). - "Ageing of the Population and Health Care Expenditure: a Red Herring?”, Health Economics, 8: pp. 485-496. 


\section{Appendices \\ A Variables Potentially used in the Estimations}

\section{A.1 Short Summary of the Variables}

- Age group

- Gender

- Marital status (abbreviated mstatus)

- Size of household (abbreviated hhsize)

- Level of education

- Social and occupational group of the head of household (following the usual

French Standard Occupational Classification, abbreviated SOC)

- Household net income per consumption unit (abbreviated Income)

- Absence of supplementary coverage (abbreviated Supplcov)

- The indicators of morbidity described below

\section{A.2 The Age Groups}

- 0: 0-9 years old

- 10: 10-19 years old

- 20: 20-29 years old

- 30: 30-39 years old

- 40: 40-49 years old

- 50: 50-59 years old

- 60: 60-69 years old

- 70: 70 years old and older

\section{A.3 Socio-Demographic Characteristics}

\section{Marital status}

- 1: married or living in a couple

- 2: divorced or separate

- 3: widow / widower

- 4: single

Level of education

- 1: does not go to school, never went to school, other

- 2: kindergarten to primary school

- 3: junior high school

- 4: high school

- 5: higher education

Social and occupational group (INSEE classification)

- 1: farmers

- 2: independent workers

- 3: intellectual professions

- 4: intermediary professions 
- 5: clerks

- 6: qualified workers

- 7: non-qualified workers

Household net income per consumption unit

- 1: belonging to the $20 \%$ lowest incomes

- 2 : belonging to the middle $40 \%$ of the income distribution

- 3: belonging to the $20 \%$ highest incomes

\section{A.4 The Indicators of Morbidity}

They are eventually to be tested for adequacy in the econometric model: significancy is tested for all and exogeneity is tested for the synthetic morbidity indicators.

\section{A.4.1 The Synthetic Morbidity Indicators:}

The level of disability: (levels 5 to 7 are grouped together)

- 0: no difficulty

- 1: very small level of difficulty

- 2: small level of difficulty

- 3: experiences difficulties but lives normally

- 4: must diminish his/her domestic or professional activity

- 5: diminished activity

- 6: no domestic autonomy

- 7: confined to bed

The death risk (DR):

- 0 : level zero of death risk

- 1: very low negative prognosis

- 2: low negative prognosis

- 3: possible risk

- 4: probably negative prognosis

- 5: surely negative prognosis

The level of death risk (probability of death within the following 5 years) is elaborated by the IRDES physicians who recode the survey.

The number of illnesses (nbpath) is calculated from the list of illnesses declared by the respondent, coupled with the ones found out by the physicians recoding the survey, on the basis of other elements of the survey, such as the type of medication taken.

The self-assessed health (SAH) is captured through a grade declared by the survey individual who rates his/her health from 0 (poorest) to 10 (highest).

\section{A.4.2 The Chronic Illnesses}

The chosen chronic illnesses specifically affect the elderly. They were selected following the ICD-10 with the help of C. Sermet (M.D.) from the Irdes Institute. As the ICD (International Statistical Classification of Diseases and Related Health Problems) has changed between 1992 and 2000 from ICD-9 to ICD-10, we had for the purpose of our study to use a correspondence between the two classifications elaborated by the IRDES institute. It consists in corresponding broad groups of 
diseases; the corresponding morbidity dummy variable codes the fact of suffering from at least one disease from the group. The such groups eventually chosen are the following:

- diabetes

- chronic obstructive pulmonary disease and related diseases (abbreviated COPD)

- ischemic heart disease (abbreviated Heart)

- hypertension

- circulatory disease

- conditions associated with lipid metabolism (abbreviated Lipid)

- depression

- sleeping disorder

- cataract

- arthritis, arthropathy and/or back pain (abbreviated arthrodorso).

\section{B The Selection of Variables}

For each kind of expenditure (physician, pharmaceutical and hospital expenditure) and each step of estimation (participation and conditional expenditure), an estimation was led with all the potential variables in order to select the significant ones. The results below provide the list of the selected variables along with the ones that were eliminated, with the result of a global significance test of the latter.

For each step of analysis (participation and conditional expenditure), the exogeneity analysis uses the selected significant variables along with supplementary instruments described below (which may vary according to the equation studied).

For the final estimations and simulations, only the significant and exogenous variables were kept. This appendix recapitulates this choice process for each expenditure studied: significance analysis and exogeneity tests. Also provided are for each kind of expenditures the $R^{2}$ of the regression of the estimated inverse Mill's ratio $(\hat{\lambda})$ on the selected second step variables, that indicates the degree of correlation of the two used to assess the validity of the GLM.

\section{B.1 Physician Expenditures}

\section{B.1.1 Significance Analysis}

\section{Participation (probit)}

Selected: age, income, SOC, hhsize, education, mstatus, hypertension, lipid, nbpath, supplcov

Eliminated: gender, COPD, heart, circulatory disease, depression, sleeping disorder, cataract, arthrodorso, DR, disability, SAH, diabetes 
Test for $\mathrm{H}_{0}$ : the eliminated variables are not significant: $\operatorname{chi} 2(12)=15.14$, $\mathrm{p}=0.2339$

\section{Conditional expenditure}

Selected: age, gender, SOC, education, depression, disability, nbpath, SAH, supplcov

Eliminated: income, diabetes, COPD, heart, hypertension, circulatory disease, lipid, sleeping disorder, cataract, arthrodorso, DR, hhsize, mstatus

$\underline{\text { Test for }}_{\mathrm{o}}$ : $\operatorname{chi} 2(16)=20.12, \mathrm{p}=0.2148$

$R^{2}$ of the $(\hat{\lambda})$ regressed on the second step variables: $R^{2}=0.7568$ (the correlation coefficient between the two is thus $\sqrt{0.7568}=0.8799$

\section{B.1.2 Exogeneity Test of the Synthetic Morbidity Indicators and Suppl. Coverage}

\section{Participation (probit)}

Instruments: head of household status (working, unemployed, non-working, the reference being retired), smoking, receiving minimum benefit payment

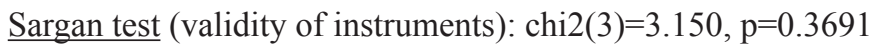

Weak instruments: $\operatorname{chi} 2(10)=415.05, \mathrm{p}=0.0000$

Tested variables: nbpath, supplcov

Exogenous variables: nbpath, supplcov

Rivers \& Vuong test: $\operatorname{chi} 2(2)=1.26, \mathrm{p}=0.5336$

\section{Conditional expenditure}

Instruments: head of household status (working, unemployed, non-working, the reference being retired), smoking, receiving minimum benefit payment, height, BMI (regular, overweight, obesity, the reference being underweight)

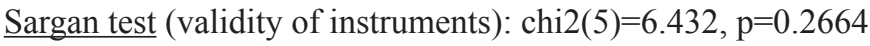

Weak instruments: $\operatorname{chi} 2(36)=836.59, \mathrm{p}=0.0000$

Tested variables: disability, nbpath, SAH, supplcov

Exogenous variables: nbpath, SAH, supplcov

Hausman test: $\operatorname{chi} 2(5)=7.29, \mathrm{p}=0.1996$

\section{B.2 Pharmaceutical Expenditures}

\section{B.2.1 Significance Analysis}

\section{Participation (probit)}

Selected: age, gender, SOC, hhsize, education, mstatus, diabetes, hypertension, lipid, arthrodorso, nbpath, SAH, supplcov 
Eliminated: income, COPD, heart, circulatory disease, depression, sleeping disorder, cataract,DR, disability

$\underline{\text { Test for } \mathrm{H}_{\underline{0}}}$ : $\operatorname{chi} 2(10)=5.25, \mathrm{p}=0.8738$

\section{Conditional expenditure}

Selected: age, gender, hhsize, education, diabetes, hypertension, lipid, depression, arthrodorso, DR, disability, nbpath, SAH

Eliminated: income, SOC, supplcov, COPD, heart, circulatory disease, sleeping disorder, cataract, mstatus

$\underline{\text { Test for } \mathrm{H}_{\mathrm{o}}}$ : $\operatorname{chi} 2(17)=13.19, \mathrm{p}=0.7233$

$R^{2}$ of the $(\hat{\lambda})$ regressed on the second step variables: $R^{2}=0.7267$ (the correlation coefficient between the two is thus $\sqrt{0.7267}=0.8525$ )

\section{B.2.2 Exogeneity Test of the Synthetic Morbidity Indicators and Suppl. Coverage}

Participation (probit)

Instruments: head of household status (working, unemployed, non-working, the reference being retired), smoking, receiving minimum benefit payment

Sargan test (validity of instruments): $\operatorname{chi} 2(2)=1.059, \mathrm{p}=0.5889$

Weak instruments: $\operatorname{chi} 2(15)=631.81, \mathrm{p}=0.0000$

Tested variables: nbpath, SAH, supplcov

Exogenous variables: nbpath, SAH, supplcov

Rivers \& Vuong test: $\operatorname{chi} 2(3)=1.56, \mathrm{p}=0.6687$

\section{Conditional expenditure}

Instruments: head of household status (working, unemployed, non-working, the reference being retired), smoking, receiving minimum benefit payment, height, BMI (regular, overweight, obesity, the reference being underweight)

Sargan test (validity of instruments): $\operatorname{chi} 2(5)=7.488, \mathrm{p}=0.1868$

Weak instruments: $\operatorname{chi} 2(36)=1040.39, \mathrm{p}=0.0000$

Tested variables: DR, disability, nbpath, $\mathrm{SAH}$

Exogenous variables: disability, nbpath, $\mathrm{SAH}$

Hausman test: $\operatorname{chi} 2(5)=9.47, \mathrm{p}=0.0917$

\section{B.3 Hospital Expenditures}

\section{B.3.1 Significance Analysis}

\section{Participation (probit)}

Selected: age, gender, hhsize, education, mstatus, diabetes, lipid, cataract, arthrodorso, DR, disability, nbpath, SAH 
Eliminated: income, SOC, supplcov, COPD, heart, hypertension, circulatory disease, depression, sleeping disorder

$\underline{\text { Test for } \mathrm{H}_{\mathrm{o}}}$ : $\operatorname{chi} 2(15)=15.57, \mathrm{p}=0.4115$

\section{Conditional expenditure}

Selected: age, education, hypertension, arthrodorso, disability, nbpath

Eliminated: gender, income, supplcov, diabetes, COPD, heart, circulatory disease, lipid, sleeping disorder, cataract, DR, SAH, hhsize, mstatus, SOC, depression

Test for $\mathrm{H}_{\mathrm{o}}$ : $\operatorname{chi} 2(24)=32.57, \mathrm{p}=0.1135$

$\mathrm{R}^{2}$ of the $(\hat{\lambda})$ regressed on the second step variables: $R^{2}=0.7579$ (the correlation coefficient between the two is thus $\sqrt{0.7579}=0.8706$ )

\section{B.3.2 Exogeneity Test of the Synthetic Morbidity Indicators and Suppl. Coverage}

\section{Participation (probit)}

Instruments: head of household status (working, unemployed, non-working, the reference being retired), smoking, receiving minimum benefit payment, height, BMI (regular, overweight, obesity, the reference being underweight)

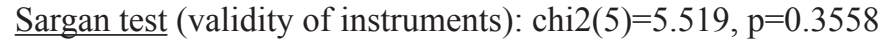

Weak instruments: $\operatorname{chi} 2(36)=1426.97, \mathrm{p}=0.0000$

Tested variables: DR, disability, nbpath, SAH

Exogenous variables: DR, disability, nbpath, SAH

Rivers \& Vuong test: $\operatorname{chi} 2(4)=3.20, \mathrm{p}=0.5249$

\section{Conditional expenditure}

Instruments: head of household status (working, unemployed, non-working, the reference being retired)smoking, receiving minimum benefit payment, height, BMI (regular, overweight, obesity, the reference being underweight)

Sargan test (validity of instruments): $\operatorname{chi} 2(7)=7.023, \mathrm{p}=0.4265$

Weak instruments: $\operatorname{chi} 2(18)=94.30, \mathrm{p}=0.0000$

Tested variables: disability, nbpath

Exogenous variables: disability, nbpath

Hausman test: $\operatorname{chi} 2(2)=0.19, p=0.9115$ 
